\title{
How friendship is defined matters for predicting intergroup attitudes: Shared activities and mutual trust with cross-ethnic peers during late childhood and early adolescence
}

International Journal of Behavioral Development 2019, Vol. 43(2) 128-135

(C) The Author(s) 2018

Article reuse guidelines: sagepub.com/journals-permissions DOI: $|0.1| 77 / 01650254|880247|$ journals.sagepub.com/home/jbd

(S)AGE

\author{
Jeanine Grütter' and Linda R. Tropp ${ }^{2}$
}

\begin{abstract}
We examined how two different definitions of cross-ethnic friendships, namely reciprocal peer nominations for shared activities and mutual trust, predict attitudes towards immigrant students among non-immigrant Swiss children and early adolescents $(N=309)$. Among both Swiss children and early adolescents, only the number of mutually trusting peer nominations with immigrant students, but not the number of mutual nominations for shared activities, positively predicted inclusive intergroup attitudes. In addition, the perception of cooperation on a common goal in the classroom positively correlated with the number of cross-ethnic-but not same-ethnic-friends whom students trusted. We discuss the implications of our findings in relation to developmental research on the antecedents of intergroup attitudes and positive cross-ethnic relationships among children and early adolescents.
\end{abstract}

Keywords

Shared activities, mutual trust, intergroup attitudes, cooperation

\section{Introduction}

Decades of research on intergroup contact show that cross-group friendships, defined as friendships among students from different social groups (e.g., ethnicity, race, nationality), can foster positive intergroup attitudes (Davies, Tropp, Aron, Pettigrew, \& Wright, 2011). However, it is possible that the extent to which crossgroup friendships, and cross-ethnic friendships in particular, yield such positive outcomes could depend on how children define friendship, as well as their developmental stage. Meta-analytic research suggests that cross-ethnic interactions are especially likely to predict more positive intergroup attitudes among children in middle and late childhood, while positive effects of cross-ethnic interactions may be less pronounced among adolescents (Raabe \& Beelmann, 2011). It remains unclear whether these divergent effects of cross-ethnic friendships on intergroup attitudes among children and adolescents reflect differences in respondents' ages, or differences in how children and adolescents understand friendship. As the meaning of friendship undergoes developmental change (Rubin, Bukowski, \& Bowker, 2015), different definitions of cross-ethnic friendship may differentially predict intergroup attitudes for different age groups.

Prior studies have not considered that certain features of crossethnic friendships may gain prominence at different developmental stages; thus, it remains unclear how different definitions of crossethnic friendships may correspond with intergroup attitudes during different developmental periods. Research on children's and adolescents' conceptions about friendship and the factors related to friendship emergence suggests that engaging in common activities (e.g., shared play) can provide a foundation for friendship development during both childhood and adolescence, whereas building trust becomes a more salient feature of friendships during the transition to adolescence (Rubin et al., 2015). In light of such developmental trends, the present research examines how distinct definitions of friendship may differentially predict intergroup attitudes among children and early adolescents; here, we focus specifically on friendships defined in terms of shared activities and mutual trust.

\section{Shared Activities and Mutual Trust as Distinct Definitions of Cross-Ethnic Friendships}

The first aim of this study is to identify the unique roles of two distinct definitions of cross-ethnic friendships in predicting intergroup attitudes: shared activities and mutual trust. Importantly, we examine this question using a peer nomination approach, focusing only on relationships that are mutually reported (Bagwell \& Bukowski, 2018). Most prior studies on cross-ethnic friendship have relied on students' self-reports of friendship (e.g., students

\footnotetext{
I Institute for Diversity in Education, University of Teacher Education Lucerne, Switzerland

${ }^{2}$ Department of Psychological and Brain Sciences, University of Massachusetts Amherst, USA
}

\section{Corresponding author:}

Jeanine Grütter, Institute for Diversity in Education, University of Teacher Education, Töpferstrasse $10 \mathrm{CH}-6004$ Lucerne, Switzerland.

Email: jeanine.gruetter@phlu.ch 
report how many cross-ethnic friends they have); however, since friendship is defined as a reciprocal relationship, such measures only capture the perspective of one student and do not necessarily represent the presence of a mutually recognized friend relationship among both parties (Aboud, Mendelson, \& Purdy, 2003; Rubin et al., 2015). In addition, even if friendship is operationalized by students' reciprocal friendship nominations, the criteria by which the presence of a friendship is defined is not always clear because children and adolescents may have different conceptions of what a friend means (Rubin et al., 2015). Therefore, in the present research, friendship is defined and measured in terms of students' reciprocal peer nominations for shared activities, and separately, in terms of students' reciprocal peer nominations for mutual trust.

In part, we focus on friendship as defined in terms of engaging in shared activities because previous research indicates that shared activities represent a fundamental indicator for distinguishing between friend and non-friend relationships among both children and early adolescents (McDougall \& Hymel, 2007; Newcomb \& Bagwell, 1995). Moreover, asking children to nominate peers with whom they share activities has a long tradition in friendship research, where prior studies show that the number of reciprocal peers with whom children spend the most time is an important precursor of positive adjustment and social inclusion (Laursen, Bukowski, Aunola, \& Nurmi, 2007).

We also focus on mutual trust as a definition of friendship that relates to children's and early adolescents' interpretation of social interactions (Carlo, Randall, Rotenberg, \& Armenta, 2010; Poulin $\&$ Chan, 2010). Prior studies with children and adults have used measures of self-disclosure to represent close friendships and relationships based on trust (see Berndt \& Hanna, 1995; Davies \& Aron, 2016). Children are also likely to reciprocate nominations of trust with peers among whom they keep and share secrets (Betts \& Rotenberg, 2008). Additionally, children who perceive each other as trustworthy are more likely to cooperate and initiate personal and confidential interactions, and mutual trust longitudinally predicts children's perspective-taking, empathy, and helpfulness (Carlo et al., 2010). Accordingly, we expect to observe a stronger link between friendship and intergroup attitudes when friendship is defined in terms of children's and adolescents' mutually trusting cross-ethnic relationships than when it is defined in terms of cross-ethnic peers with whom they share activities.

A second aim of this study is to examine whether age-related trends in the effects of cross-ethnic friendships on intergroup attitudes can be explained by developmental differences that characterize the relative importance of shared activities and mutual trust during late childhood and early adolescence (Rubin et al., 2015). Since mutual trust reflects growing intimacy in friendships that develops further with the transition into adolescence (Rubin et al., 2015; Zarbatany, McDougall, \& Hymel, 2000), we expect that the link between intergroup attitudes and students' cross-ethnic friendships defined in terms of mutual trust will be stronger among early adolescents than among children.

\section{Shared Activities and Mutual Trust in Cooperative Classroom Environments}

A third aim of this study is to examine how the prominence of shared activities and mutual trust in cross-ethnic friendships may depend on features of the social environment. Although previous research has emphasized the importance of cross-ethnic friendships for shifting intergroup attitudes (e.g., Pettigrew \& Tropp, 2006), little is known regarding what predicts these important relationships (Leman \& Cameron, 2017). Nonetheless, other work suggests that perceiving the social environment to embody conditions such as cooperation and common goals can enhance the tendency for intergroup contact to foster positive intergroup attitudes among children and adolescents (Tropp \& Prenovost, 2008). Indeed, cooperative structures in the classroom can promote pro-social behavior, sharing of information, and trusting interactions among students (Johnson, 2003; Roseth, Johnson, \& Johnson, 2008). Moreover, cooperative classroom environments can enhance the popularity of ethnic minority children (Oortwijn, Boekaerts, Vedder, \& Fortuin, 2008) and may also contribute to the development of children's cross-ethnic friendships (Jugert, Noack, \& Rutland, 2011). Extending this work, the present research considers how the perception of cooperation in the classroom contributes to cross-ethnic friendships among children and early adolescents, by examining more specifically whether students who perceive that students in their classroom generally cooperate had more cross-ethnic friendship nominations for shared activities and mutual trust than students who perceived lower levels of cooperation among students in their classroom.

\section{Shared Activities, Mutual Trust, and Cooperative Classrooms: Predicting Intergroup Attitudes Among Swiss Students in Relation to Immigrants}

This study was conducted in Switzerland, where, according to national statistics, $24.9 \%$ of the population is non-Swiss (i.e., of a nationality other than Swiss) and an estimated $35 \%$ of the population has a migration background (i.e., at least one of the parents was born in another country; Swiss Federal Statistical Office, 2016). This multicultural social context may not only offer greater opportunities for intergroup contact, but may also give rise to prejudice and discrimination towards immigrant minorities (Sarrasin et al., 2012). Generally, students with a migration background have lower social positions compared to Swiss students and are at a higher risk for segregated schooling due to low achievement (Eckhart, 2005). By focusing on how different friendship properties predict intergroup attitudes among Swiss students, the present research may offer guidance regarding how to curb social exclusion and isolation of immigrant students. Moreover, this research may also shed light on the conditions of classroom environments that are most likely to promote cross-ethnic friendships.

\section{Method}

\section{Sample and Procedure}

Participants were recruited from 20 school classes in 11 primary public schools (grades one to six) in five school districts from the Canton of Zurich in Switzerland in 2010. These school districts were comparable in terms of their percentage of foreign nationals (i.e., 18-26\%), number of students, and average socio-economic status of students (Educational Statistics of the Canton of Zurich, 2016). Participants were divided in two age groups: late childhood (range: $7-9$ years, $n=145 ; M_{\text {age }}=8.39$ years; $S D=0.76,51 \%$ girls) and early adolescence (range: $10-13$ years, $n=164 ; M_{\text {age }}=$ 10.65 years; $S D=0.82,49 \%$ girls). 
Table I. Correlations of study and control variables among Swiss participants.

\begin{tabular}{|c|c|c|c|c|c|c|c|c|}
\hline & Range & $M(S D)$ & I. & 2. & 3. & 4. & 5. & 6. \\
\hline I. Sex & & - & & & & & & \\
\hline 2. Age group & & - & 0.01 & & & & & \\
\hline 3. Shared activities & $0.0-3.0$ & $0.5 I(0.74)$ & $-0.14^{*}$ & 0.07 & & & & \\
\hline 4. Mutual trust & $0.0-3.0$ & $0.22(0.49)$ & $0.12^{*}$ & 0.09 & $0.53^{*}$ & & & \\
\hline 5. Intergroup attitudes & $1.0-5.0$ & $3.00(0.87)$ & 0.07 & 0.10 & 0.04 & $0.16^{*}$ & & \\
\hline 6. Perceived cooperation & $2.0-5.0$ & $3.73(0.78)$ & 0.07 & -0.08 & -0.02 & $0.10^{*}$ & $0.18^{*}$ & \\
\hline 7. Classroom ethnic diversity & $0.17-0.72$ & $0.50(0.12)$ & 0.01 & -0.07 & $0.19 *$ & $0.16^{*}$ & 0.08 & -0.03 \\
\hline
\end{tabular}

Note: $n=309$ for sex, age group, shared activities, mutual trust, and classroom ethnic diversity; $n=300$ for intergroup attitudes and perceived cooperation. Sex $(0=$ male, I = female), Age group ( 0 = late childhood, I = early adolescence).

$* p<0.05$, two-tailed.

M: mean; SD: standard deviation.

In order to determine whether any student had a migration background, teachers indicated for each of their students whether they had a migration background and students indicated what languages they spoke with their parents. Based on this information, we identified 309 non-immigrant Swiss students and an additional 125 students with a migration background (Eastern Europe: 35\%, Southern Europe: 29\%, Northern/Western Europe: 23\%, Arab/ Asian regions: $13 \%$ ). Immigrant students were not included in statistical analyses, because they represented 22 different nationalities, and there were not enough students from any single nationality or geographical region to conduct analyses comparable to those for Swiss students. However, immigrant students are mentioned here because their data were used to determine mutual reports of shared activities and trust and to estimate classroom ethnic diversity.

Primary caregivers' informed consent was obtained and participating children were asked for oral assent. Only $2.5 \%$ of the parents refused consent, and their children were removed from the study and any peer nomination data related to their children was not analyzed. Five trained research assistants conducted individual face-to-face interviews with participating students. Participating students answered questions regarding their classroom environment, their peer relations, and their intergroup attitudes.

\section{Measures}

Correlations, means and standard deviations of the primary study variables are displayed in Table 1.

Intergroup attitudes. Students listened to a story about children from another school class and were asked to imagine being a member of this class. One of the classmates was described as being an immigrant student - that is, knowing another language better and sometimes having trouble understanding Swiss German. Using a five-point "smiley scale," children rated two versions of this hypothetical classmate-one male, and one female in random order - on three items to assess how they felt about interacting with this student in social activities (i.e., "How much would you like to play with this student?", "How much would you like to spend your break time with this student?", "How much would you like to invite this student to your birthday party?", $\alpha=0.79$; adapted from Cameron, Rutland, Brown, \& Douch, 2006, Chen \& Graham, 2015, and Grütter \& Meyer, 2014). This measure represents how willingly students would interact with an out-group member, with higher values indicating more favorable attitudes about interacting with immigrant students.
Cross-ethnic peer nominations: shared activities and mutual trust. Shared activities and mutual trust were identified based on students' mutual peer nominations in response to two separate questions regarding shared activities (i.e., "With whom do you [play/hang out] during break time?") and mutual trust (i.e., "With whom do you share your secrets?"); with regard to the shared activities question, the term "play" was used for children, and the term "hang out" was used for early adolescents. For each question, students chose as many names as they wished from their class, in which both children and early adolescents spent the majority of their time during school. Reciprocated nominations between Swiss and immigrant students and between Swiss students were identified and tallied separately for each question, to distinguish empirically between friendship nominations based on shared activities and mutual trust (for similar procedures see Aboud et al., 2003; Grütter, Gasser, Zuffiano, \& Meyer, 2017). Specifically, each individual student received two count scores, calculated separately for reciprocal nominations based on shared activities and reciprocal nominations based on trust.

Thirty-nine percent of the Swiss children had at least one reciprocal nomination with an immigrant student in reports of shared activities (range of average number of nominations across classrooms $=0.17-2.0$ ) and $19 \%$ had at least one reciprocal nomination with an immigrant student in regard to trust (range of average number of nominations across classrooms $=0-0.89$ ). Sixteen percent of students $(n=50)$ reported at least one cross-ethnic friend for both shared activities and mutual trust, whereas $53 \%$ of students $(n=164)$ reported at least one same-ethnic friend for both shared activities and mutual trust. There was a partial overlap between shared activities and mutual trust for students who reported at least one same-ethnic or one cross-ethnic friendship. Of the students who reported at least one same-ethnic peer for mutual trust, $90 \%$ also reported at least one same-ethnic peer for shared activities; by contrast, $52 \%$ of the students who reported at least one same-ethnic peer for shared activities did not nominate a same-ethnic peer for mutual trust. Similarly, of the students who nominated at least one cross-ethnic peer for mutual trust, $86 \%$ also nominated at least one cross-ethnic peer for shared activities; at the same time, $28 \%$ of the students who reported at least one friendship with a cross-ethnic peer for shared activities did not nominate cross-ethnic peers for mutual trust. Additional information regarding the average number of peer nominations for mutual trust and shared activities and their overlap can be found in the Online Appendices S1, S2-A, and S2-B.

Perceived cooperation in the classroom. To assess perceived cooperation in the classroom, students responded to the following 
question: "All the children in my class cooperate toward a common goal" ( 1 = "not at all" to 5 = "very much"; see Jugert et al., 2011). Since there was no significant variance in perceived cooperation between classrooms $(I C C(1)=0.001)$, we did not aggregate students' responses and used the individual perception of a common classroom goal as an indicator of perceived cooperation in our analyses (see Lüdtke, Robitzsch, Trautwein, \& Kunter, 2009).

Classroom ethnic diversity. Despite having a very similar percentage of immigrant students across the five school districts where this research was conducted, there was still variation regarding the number of immigrant students between the 20 different classrooms (range $=10-60 \%$ ). Therefore, we controlled for the ethnic diversity of the classroom in our statistical analyses. Since our immigrant sample was very diverse with students from over 22 different nationalities, we used a measure that takes this ethnic diversity of the classroom into account. However, since the sample of immigrant students was small, we determined four categories of major immigrant groups in Switzerland based on geographic regions that have been specified in prior research (Southern Europe, Northern and Western Europe, Eastern Europe, and Asia/Middle East; see Binggeli, Krings, \& Scesny, 2014). Then, we calculated Simpson's Diversity Index by estimating proportions of the four immigrant categories and Swiss students in each classroom (Simpson, 1949). This measure captures the relative representation of the Swiss and immigrant student groups in classrooms, ranging from 0 (no diversity, all students in the class are Swiss) to closer to 1 (total diversity, all students are from different geographic origins and represented evenly). In the present case, with five different categories (four categories of immigrant origin and Swiss origin), the maximum possible score on the diversity index would be 0.8 , which would mean that all five groups are represented evenly across classrooms. Classroom diversity indexes ranged from 0.17 to 0.72 , and they were very similar among both age-groups (i.e., $M_{\text {childhood }}=0.53$, $\left.S D_{\text {childhood }}=0.10 ; M_{\text {adolescence }}=0.52, S D_{\text {adolescence }}=0.14\right)$.

\section{Data Analytic Approach}

To test our first two study aims - how the number of nominations of shared activities and mutual trust between Swiss and immigrant students relate to Swiss students' intergroup attitudes, and whether these relations would be moderated by age-we used hierarchical linear models, controlling for ethnic classroom diversity. Each student received two count scores for the numbers of reciprocal crossethnic friendship nominations, calculated separately for reciprocal nominations based on shared activities and those based on mutual trust. These numbers of reciprocal cross-ethnic nominations for shared activities and mutual trust were entered as separate predictors for intergroup attitudes at the first step of analysis; interaction terms between age and shared activities, and age and mutual trust, were then entered at the second step, to test whether age group would moderate relations between either of these two definitions of cross-ethnic friendship and intergroup attitudes. The intra-class correlation $(I C C(1))$ reflecting the proportion of overall variance explained by classroom membership (Bliese, 2000) was $2 \%$ $(I C C(1)=0.02)$. The variance of the intercept was not significantly larger than zero, $F(19,280)=1.19, p=0.26$; nonetheless, since we included classroom ethnic diversity as a control variable at the classroom level, we still considered the hierarchical structure of the data. Moreover, given prior work suggesting sex differences in friendship networks (Rubin, Bukowski, Parker, \& Bowker, 2006), we controlled for possible sex differences in examining mutual nominations for shared activities and trust as predictors for intergroup attitudes.

We then examined our third study aim, namely whether perceived cooperation in the classroom would predict the number of cross-ethnic nominations for shared activities and mutual trust between Swiss and immigrant children. Here, we observed that $20 \%$ of the variance in the number of reciprocal nominations for shared activities $(\operatorname{ICC}(1)=0.20, F(19,289)=4.79, p<0.001)$ and $10 \%$ of the variance in the number of reciprocal nominations for trust $(\operatorname{ICC}(1)=0.10, F(19,289)=2.69, p<0.001)$ was due to differences between classrooms. Thus, we employed a hierarchical data structure when predicting cross-ethnic nominations for shared activities and mutual trust (Bliese, 2000). These dependent variables were not normally distributed; we therefore tested which nonlinear model fit our data best and chose a generalized nonlinear model using a Poisson distribution (Long \& Freese, 2006). We controlled for sex, age group, classroom ethnic diversity, and intergroup attitudes, since previous research suggests a bidirectional relation between cross-ethnic friendship and intergroup attitudes (Pettigrew \& Tropp, 2006). However, since "intergroup attitudes" was not a significant predictor for the number of cross-ethnic relationships based on mutual trust and shared activities, it was not included in the final model. Additionally, because a larger percentage of students had reciprocal nominations for trust if they also had reciprocal nominations for shared activities (see Table S2-A), we examined whether a model that included nominations for shared activities would fit the data better than a model without nominations for shared activities (see Online Appendix S5). Since this was the case (see Table S5), we controlled for nominations for shared activities when predicting nominations for mutual trust. All these analyses regarding our third study aim were tested in a hierarchical path model. We conducted our analyses with the statistical softwares R and MPLUS (Muthén \& Muthén, 2014; $\mathrm{R}$ Development Core Team, 2015). A total of nine students had missing data on one of the relevant measures and were therefore excluded from data analysis.

\section{Results}

\section{Shared Activities and Mutual Trust as Predictors for Intergroup Attitudes}

At the first step of the hierarchical model, only the number of mutual trust nominations, but not the number of nominations for shared activities, significantly predicted more inclusive intergroup attitudes (see Table 2, Step 1). We can interpret the effect of crossethnic nominations for mutual trust as significantly predicting intergroup attitudes beyond the effect reciprocal cross-ethnic nominations of shared activities. Because there was some overlap between peer nominations for shared activities and mutual trust among cross-ethnic peers, we also conducted separate analyses to test whether shared activities and mutual trust would predict intergroup attitudes (see Online Appendix Table S3). Importantly, when cross-ethnic nominations for shared activities is by itself entered into the model, it does not emerge as a significant predictor of intergroup attitudes (see Table S3, Model 1). Thus, it is not the case that the inclusion of cross-ethnic nominations for mutual trust inhibits the potential of cross-ethnic nominations of shared activities to predict intergroup attitudes. By contrast, when only crossethnic nominations for mutual trust is entered into the model, it 
Table 2. Hierarchical linear random coefficient models predicting Swiss children's and early adolescents' intergroup attitudes.

\begin{tabular}{|c|c|c|c|c|c|c|}
\hline & \multicolumn{3}{|c|}{ Step I } & \multicolumn{3}{|c|}{ Step 2} \\
\hline & $\gamma[95 \% \mathrm{Cl}]$ & $d f$ & $t$ & $\gamma[95 \% \mathrm{Cl}]$ & $d f$ & $t$ \\
\hline Sex & $0.07[-0.13-0.28]$ & 276 & 0.71 & $0.07[-0.13-0.28]$ & 274 & 0.71 \\
\hline Age group & $0.15[-0.05-0.36]$ & 276 & 1.52 & $0.16[-0.08-0.40]$ & 274 & 1.30 \\
\hline Shared activities & $-0.07[-0.23-0.09]$ & 276 & -0.90 & $-0.16[-0.84-0.19]$ & 274 & -1.33 \\
\hline Mutual trust & $0.30[0.06-0.54]$ & 276 & $2.45^{*}$ & $0.59[0.17-1.79]$ & 274 & $2.88 *$ \\
\hline Classroom ethnic diversity & $0.47[-0.4 \mid-1.34]$ & 18 & 1.12 & $0.49[-0.36-1.35]$ & 18 & 1.21 \\
\hline Age $*$ activities & & & & $0.17[-0.15-0.48]$ & 274 & 1.05 \\
\hline Age $*$ trust & & & & $-0.42[-0.90-0.06]$ & 274 & -1.73 \\
\hline-2 logLikelihood & 769.36 & & & 769.46 & & \\
\hline $\mathrm{AIC}$ & 785.36 & & & 789.46 & & \\
\hline $\mathrm{BIC}$ & 814.83 & & & 826.22 & & \\
\hline McFadden's pseudo- $R^{2}$ & 0.05 & & & 0.05 & & \\
\hline
\end{tabular}

Note: $n_{\text {level } 1}=300, n_{\text {level } 2}=20$. Sex $(0=$ male, $I=$ female $)$, Age group $(0=$ late childhood, $I=$ early adolescence $)$. The variable classroom ethnic diversity was centered at the grand sample mean. We report McFadden's overall pseudo- $R^{2}$ for the comparison of effect sizes (Long \& Freese, 2006).

$*_{p}<0.05$, two-tailed.

$\mathrm{Cl}$ : confidence interval; $\mathrm{df}$ : degrees of freedom; $t$ : statistical distribution used for hypothesis testing; AIC: Akaike Information Criterion; BIC: Bayesian Information Criterion.

Table 3. Hierarchical generalized linear path models regressing the number cross-group friendships for the friendship definitions "shared activities" and "mutual trust" on perceived cooperation while controlling for sex, age group, and classroom ethnic diversity.

\begin{tabular}{|c|c|c|c|c|}
\hline & \multicolumn{2}{|c|}{ Shared activities } & \multicolumn{2}{|c|}{ Mutual trust } \\
\hline & $\exp (B)[95 \% C l]$ & $z$ & $\exp (B)[95 \% C l]$ & $z$ \\
\hline Sex & $0.67[0.46-0.97]$ & $-2.13^{*}$ & $2.17[1.33-3.54]$ & $3.14 * *$ \\
\hline Age group & $1.21[0.77-1.90]$ & 0.82 & $1.15[0.68-1.95]$ & 0.52 \\
\hline Perceived cooperation & $1.01[0.83-1.23]$ & 0.05 & $1.37[1.02-1.84]$ & $2.09 *$ \\
\hline Shared activities & & & 2.71 [2.14-3.42] & $8.53 * * *$ \\
\hline Classroom ethnic diversity & 11.09 [2.14-57.54] & $2.85^{* *}$ & $2.46[0.21-28.15]$ & 0.72 \\
\hline-2 logLikelihood & 826.62 & & & \\
\hline $\mathrm{AIC}$ & 848.62 & & & \\
\hline $\mathrm{BIC}$ & 889.364 & & & \\
\hline$R_{\text {LR(Nagelkerke) }}^{2}$ & 0.24 & & & \\
\hline
\end{tabular}

Note: $n_{\text {level I }}=300, n_{\text {level } 2}=20$. Model family $=$ Poisson. For the ease of interpretability of the model estimates, the exponentiated coefficients are reported. This value expresses the incidence rate ratio; thus, the expected increase or decrease rate factor in the number of friendships when the independent variable increases by I unit. For example, girls are expected to have a rate 2.17 times greater for the number of mutual trust nominations than boys. The $95 \% \mathrm{Cl}$ values are reported for the incidence rate ratio. Sex $(0=$ male, I = female), Age group $(0=$ late childhood, I = early adolescence). The variable classroom ethnic diversity was centered at the grand sample mean.

${ }^{*} p<0.10,{ }^{* * p} p<0.05, * * * p<0.01$, two-tailed

$\operatorname{Exp}(B)$ : incidence rate ratio; $\mathrm{Cl}$ : confidence interval; z: statistical distribution used for hypothesis testing; AIC: Akaike Information Criterion; BIC: Bayesian Information Criterion;

$R_{\operatorname{LR}(\text { Nagelkerke })}^{2}=$ Nagelkerke's modified pseudo- $R^{2}$ for nonlinear models.

emerges as a significant predictor of intergroup attitudes (see Table S3, Model 2), and it remains significant even when cross-ethnic nominations for shared activities are entered into the model (see Table 2, Step 1). Moreover and contrary to our expectation, the predictive effect of mutual trust nominations on intergroup attitudes did not vary depending on participants' age group (see Table 2, Step 2).

\section{Perceived Cooperation as a Predictor for Shared Activities and Mutual Trust}

Table 3 shows that perceived cooperation on a common goal predicted only mutual trust - and not shared activities. To test for the significance of this predictor, an additional Wald test was employed, Wald $(1)=4.36, p=0.04$. Thus, the more Swiss students perceived that all students in the classroom cooperate on a common goal, the more mutually trusting friendship nominations they had with immigrant children. In addition, Swiss students who had mutual nominations for shared activities also had significantly more mutual trust nominations. Lastly, girls had significantly fewer reciprocal nominations for shared activities and more reciprocal nominations for mutual trust than boys (see Table 3). As a supplemental analysis, we also tested whether perceived cooperation in the classroom would generally predict more nominations among Swiss students in relation to other Swiss students (i.e., sameethnic peer nominations for shared activities and mutual trust); these analyses did not show any significant effects of perceived cooperation in the classroom on shared activities or mutual trust among Swiss students in relation to other Swiss students (see Online Appendix Table S4). 
Since perceived cooperation predicted mutual trust nominations between Swiss and immigrant students, and mutual trust in turn predicted positive intergroup attitudes, we also tested whether the relation between perceived cooperation and intergroup attitudes was mediated by the number of cross-ethnic nominations for mutual trust. This analysis did not yield a significant mediation effect $(a b=0.09, S E=0.06, p=0.18)$.

\section{Discussion}

In this research, we examined how two different definitions of cross-ethnic friendships - friendship defined in terms of numbers of reciprocal cross-ethnic nominations for shared activities and mutual trust — predict inclusive attitudes toward immigrants among non-immigrant Swiss children and early adolescents. In addition, since cooperation has been identified as an important aspect of friendship (Laursen, 2017; Newcomb \& Bagwell, 1995), we examined whether perceived cooperation in classroom environments predicts reciprocal cross-ethnic nominations for shared activities and mutual trust.

Our findings highlight that different definitions of cross-ethnic friendship may play distinct roles in predicting students' intergroup attitudes. Friendship as defined in terms of the number of reciprocal peer nominations for mutual trust among Swiss students and their immigrant classmates predicted more inclusive attitudes among Swiss students; by contrast, friendship defined in terms of the number of reciprocal peer nominations for shared activities with immigrant classmates did not meaningfully contribute to predicting Swiss students' intergroup attitudes. This finding complements other recent work showing stronger effects of cross-ethnic friendship on early adolescents' intergroup attitudes when assessed in terms of emotional dimensions of friendship as compared to time spent with cross-ethnic friends (e.g., Chen \& Graham, 2015). However, in contrast to Chen and Graham (2015), mutual peer nominations for shared activities did not significantly predict Swiss students' intergroup attitudes in the present study. It is possible that these different patterns of results could involve the domains in which shared activities were assessed. Chen and Graham (2015) asked students to report on their activities outside of school, whereas our study asked students to report on their activities and friendships at school.

Moreover, our findings suggest that assessing reciprocal crossethnic nominations for shared activities at school—such as playing or hanging out together-may not in itself be sufficient to represent an operationalization of friendship. While positive engagement in social activities (such as play) is generally considered to be an important characteristic of friendship, students may differ in their willingness to share, cooperate or build affective ties during such interactions (McDougall \& Hymel, 2007; Newcomb \& Bagwell, 1995). Thus, future studies of cross-ethnic friendship should grant more attention to qualitative aspects of mutually reported crossethnic activities and interactions in which students are engaged. Taken together, our results suggest that researchers may need to reconsider the kinds of measures that are traditionally used to assess cross-ethnic friendships among children, given that different definitions of friendships resulted in different outcomes when predicting students' intergroup attitudes.

Furthermore, mutually trusting cross-ethnic friendships appear to play an especially important role for students' intergroup attitudes during both childhood and early adolescence. Contrary to our expectation, this study did not reveal differences between children and early adolescents in how the number of reciprocal nominations for mutual trust predicted inclusive attitudes toward immigrants. Despite other evidence that self-disclosure, intimacy and trust in friendships become especially important relationship properties during the transition to early adolescence (e.g., Rubin et al., 2015; Zarbatany et al., 2000), we did not observe a stronger relation between the number of reciprocal cross-ethnic nominations for mutual trust and intergroup attitudes among early adolescents than among children. This finding suggests that cross-ethnic friendships defined in terms of mutual trust may be an important precursor for inclusive intergroup attitudes, even at earlier stages of development. Consistent with this view, some research suggests that children start to prefer relationships that are characterized by trust during late childhood (Kahn \& Turiel, 1988). Still, future research should consider whether the characteristics that children use to define trust may vary among children and early adolescents, as its function may vary across different age groups (see Rubin et al., 2006).

Moreover, compared to girls, boys had significantly fewer reciprocal cross-ethnic nominations for mutual trust. This finding may reflect a tendency for disclosure of personal information to be more characteristic of friendships among girls than among boys (Rubin et al., 2006), whereas intimacy among boys tends to be associated with their shared play (Zarbatany et al., 2000). These trends may explain why Swiss boys had more reciprocal cross-ethnic nominations regarding shared activities than Swiss girls in this study. However, no sex differences were found in relation to reciprocal nominations for shared activities with same-ethnic peers (see Online Appendix Table S4); thus, comparisons of sex differences in cross-ethnic and same-ethnic friendships may be an important area for future research.

Our results further show that students' perception of cooperation in the classroom positively predicts greater numbers of reciprocal cross-ethnic nominations for mutual trust among Swiss students and their immigrant classmates, even while controlling for classroom ethnic diversity and students' intergroup attitudes. Thus, beyond the possibility that less biased students may be more open to cross-ethnic friendships, the finding suggests that perceiving the classroom as cooperative corresponds with a greater tendency to report mutually trusting cross-ethnic friendships. This finding is in line with other work showing that interdependent classroom activities can build positive relationships among diverse groups of students (Johnson \& Johnson, 2005). It is also notable that perceived cooperation was not associated with greater numbers of reciprocal trust nominations among Swiss students in relation to same-ethnic peers; thus, rather than generally improving social relationships in the classroom, perceived cooperation seemed especially likely to foster greater numbers of trusting relationships with cross-ethnic peers. This may be because cooperative norms promote children's identification with a common in-group identity (such as the school class), which nurtures positive attitudes toward members of other ethnic groups (Cameron et al., 2006).

Despite its contributions to the research literature, this study is not without limitations: First, the positive relation between crossethnic nominations for mutual trust and positive intergroup attitudes was relatively small in magnitude. Here, it should be emphasized that cross-ethnic friendships were defined through reciprocal peer nominations, rather than simply asking Swiss students if they had immigrant friends; prior research has shown that such peer nomination approaches to assessing cross-group 
friendships tend to yield smaller effect sizes than approaches that ask people simply to report on numbers of cross-group friends (see Davies et al., 2011).

Second, we recognize limitations associated with the fact that the findings we report are based on analyses of cross-sectional data. For instance, we observed that cross-ethnic nominations for shared activities predicted significantly greater numbers of cross-ethnic nominations for mutual trust, in a manner consistent with prior longitudinal research showing that cross-group friendships predict more positive intergroup attitudes by increasing trust (Grütter et al., 2017). Nonetheless, causal claims regarding these cannot be supported using the present data (see Table S5 and Online Appendix S5), and additional longitudinal research that allows the examination of relations between cross-ethnic nominations for shared activities and mutual trust are needed to gain greater insight regarding potential causal effects.

Third, there may be limitations associated with our decision to assess friendship in terms of the number of reciprocal nominations for shared activities and the number of reciprocal nominations for mutual trust. More in line with traditional measures (e.g., Bukowski, Hoza, \& Boivin, 1994), an alternative approach would have been to ask students to nominate their friends and to then measure friendship quality within each reported friendship. While our approach does not allow us to draw conclusions regarding relative levels of companionship and trust within any particular friendship, our results do show that different conceptual and operational definitions of friendship can meaningfully predict intergroup attitudes in different ways. Looking toward the future, researchers may therefore consider employing both strategies, in order to see how different measures of friendship may be usefully integrated toward a greater understanding of the nature and function of friendship among children and early adolescents.

Fourth, another limitation is that, due to our small and highly diverse immigrant sample, we could not meaningfully study how cross-ethnic nominations for shared activities and mutual trust predict the developing intergroup attitudes of immigrant students. Given that these students tend to have lower social positions compared to Swiss children (Eckhart, 2005), it would be important to know which kinds of friendships with Swiss children would facilitate feelings of inclusion from their perspective. Moreover, since different stereotypes are often associated with distinct immigrant groups in the Swiss context (Binggeli et al., 2014), future research could usefully examine how activity- and trust-based relationships with cross-ethnic peers might transform perceptions of youth from these different immigrant groups.

Nonetheless, on the whole, our findings suggest that mutually trusting relationships between students from different ethnic groups are crucial to promote positive intergroup attitudes during late childhood and early adolescence. In addition, perceiving cooperation in the classroom environment predicted greater numbers of mutually trusting cross-ethnic friendships among Swiss students in relation to their immigrant classmates. Still, cooperative classroom environments may represent only one of many strategies that could foster the inclusion of immigrant students. Other strategies could include individualized learning, fostering positive relationships between teachers and parents, and sensitizing teachers to issues of ethnic diversity and social inequality (Haenni Hoti, Heinzmann, Müler, \& Buholzer, 2017). Further research attention should therefore be granted to examining how varied features of classroom environments can facilitate the development of mutually trusting relationships between students from diverse ethnic backgrounds.

\section{Acknowledgments}

The authors are grateful to the undergraduate students who assisted in the data collection and to all the teachers and students who participated in the study.

\section{Funding}

The author(s) received no financial support for the research, authorship, and/or publication of this article.

\section{Supplemental Material}

Supplemental material for this article is available online.

\section{References}

Aboud, F. E., Mendelson, M. J., \& Purdy, K. T. (2003). Cross-race peer relations and friendship quality. International Journal of Behavioral Development, 27(2), 165-173.

Bagwell, C. L., \& Bukowski, W. M. (2018). Friendship in childhood and adolescence. Features, effects, and processes. In W. M. Bukowski, B. Laursen, \& K. H. Rubin (Eds.), Handbook of peer interactions, relationships, and groups (2nd ed., pp. 371-409). New York, NY: Guilford Press.

Berndt, T. J., \& Hanna, N. A. (1995). Intimacy and self-disclosure in friendships. In K. J. Rotenberg (Ed.), Disclosure processes in children and adolescents (pp. 57-77). Cambridge, England: Cambridge University Press.

Betts, L. R., \& Rotenberg, K. J. (2008). A social relations analysis of children's trust in their peers across the early years of school. Social Development, 17(4), 1039-1055.

Binggeli, S., Krings, F., \& Sczesny, S. (2014). Stereotype content associated with immigrant groups in Switzerland. Swiss Journal of Psychology, 73(3), 123-133.

Bliese, P. D. (2000). Within-group agreement, non-independence, and reliability: Implications for data aggregation and analysis. In K. J. Klein \& S. W. Kozlowski (Eds.), Multilevel theory, research, and methods in organizations (pp. 349-381). San Francisco, CA: Jossey-Bass.

Bukowski, W. M., Hoza, B., \& Boivin, M. (1994). Measuring friendship quality during pre-and early adolescence: The development and psychometric properties of the friendship quality scale. Journal of Social and Personal Relationships, 11(3), 471-484.

Cameron, L., Rutland, A., Brown, R. J., \& Douch, R. (2006). Changing children's intergroup attitudes toward refugees: Testing different models of extended contact. Child Development, 77(5), 1208-1219.

Carlo, G., Randall, B. A., Rotenberg, K. J., \& Armenta, B. E. (2010). Exploring the relations among trust beliefs, prosocial tendencies, and friendships. In K. J. Rotenberg (Ed.), Interpersonal trust during childhood and adolescence (pp. 270-294). New York, NY: Cambridge University Press.

Chen, X., \& Graham, S. (2015). Cross-ethnic friendships and intergroup attitudes among Asian American adolescents. Child Development, 86(3), 749-764.

Davies, K., \& Aron, A. (2016). Friendship development and intergroup attitudes: The role of interpersonal and intergroup friendship processes. Journal of Social Issues, 72(3), 489-510.

Davies, K., Tropp, L. R., Aron, A., Pettigrew, T. F., \& Wright, S. C. (2011). Cross-group friendships and intergroup attitudes: A meta-analytic review. Personality and Social Psychology Review, 15(4), 332-351.

Eckhart, M. (2005). Recognition and rejection in school classes. Attitudes and relationships of Swiss children and immigrant children 
[Anerkennung und ablehnung in schulklassen. Einstellungen und beziehungen von schweizer kindern und immigrantenkindern]. Bern, Switzerland: Haupt.

Educational Statistics of the Canton of Zurich. (2016). Characteristics of school municipalities. Retrieved from https://www.bista.zh.ch/_ vs/vs_sgem.aspx\#markeC.

Grütter, J., Gasser, L., Zuffiano, A., \& Meyer, B. (2017). Promoting inclusion via cross-group friendship: The role of individual change in trust and sympathy. Child Development. doi:10.1111/cdev. 12883.

Grütter, J., \& Meyer, B. (2014). Intergroup friendship and children's intentions for social exclusion in integrative classrooms: The moderating role of teachers' diversity beliefs. Journal of Applied Social Psychology, 44(7), 481-494.

Haenni Hoti, A., Heinzmann, S., Müller, M., \& Buholzer, A. (2017). Psychosocial adaptation and school success of Italian, Portuguese and Albanian students in Switzerland: Disentangling migration background, acculturation, and the school context. International Journal of Migration \& Integration, 18(1), 85-106.

Johnson, D. W. (2003). Social interdependence: The interrelationships among theory, research, and practice. American Psychologist, 58(11), 931-945.

Johnson, D. W., \& Johnson, R. T. (2005). New developments in social interdependence theory. Genetic, Social, and General Psychology Monographs, 131(4), 285-358.

Jugert, P., Noack, P., \& Rutland, A. (2011). Friendship preferences among German and Turkish preadolescents. Child Development, 82(3), 812-829.

Kahn, P. H., \& Turiel, E. (1988). Children's conceptions of trust in the context of social expectations. Merrill-Palmer Quarterly-Journal of Developmental Psychology, 34, 403-419.

Laursen, B. (2017). Making and keeping friends: The importance of being similar. Child Development Perspectives, 11(4), 282-289.

Laursen, B., Bukowski, W. M., Aunola, K., \& Nurmi, J. E. (2007). Friendship moderates prospective associations between social isolation and adjustment problems in young children. Child Development, 78(4), 1395-1404.

Leman, P. J., \& Cameron, L. (2017). Growing up with diversity: Psychological perspectives. Journal of Community and Applied Social Psychology, 27, 339-346.

Long, J. S., \& Freese, J. (2006). Regression models for categorical and limited dependent variables using Stata (2nd ed.). College Station, TX: Stata Press.

Lüdtke, O., Robitzsch, A., Trautwein, U., \& Kunter, M. (2009). Assessing the impact of learning environments: How to use student ratings of classroom or school characteristics in multilevel modeling. Contemporary Educational Psychology, 34(2), 120-131.

McDougall, P., \& Hymel, S. (2007). Same-gender versus cross-gender friendship conceptions: Similar or different? Merrill-Palmer Quarterly-Journal of Developmental Psychology, 53(3), 347-380.
Muthén, L. K., \& Muthén, B. O. (2014). Mplus user's guide (7th ed.). Los Angeles, CA: Muthén \& Muthén.

Newcomb, A. F., \& Bagwell, C. L. (1995). Children's friendship relations: A meta-analytic review. Psychological Bulletin, 117(2), 306-347.

Oortwijn, M. B., Boekaerts, M., Vedder, P., \& Fortuin, J. (2008). The impact of a cooperative learning experience on pupils' popularity, non-co-operativeness, and interethnic bias in multiethnic elementary schools. Educational Psychology, 28(2), 211-221.

Pettigrew, T. F., \& Tropp, L. R. (2006). A meta-analytic test of intergroup contact theory. Journal of Personality and Social Psychology, 90(5), 751-783.

Poulin, F., \& Chan, A. (2010). Friendship stability and change in childhood and adolescence. Developmental Review, 20, 257-272.

R Development Core Team. (2015). R: A language and environment for statistical computing [Computer Software]. Retrieved 5 April 2015, Retrieved from http://www.R-project.org. Vienna, Austria.

Raabe, T., \& Beelmann, A. (2011). Development of ethnic, racial, and national prejudice in childhood and adolescence: A multinational meta-analysis of age differences. Child Development, 82(6), 1715-1737.

Roseth, C. J., Johnson, D. W., \& Johnson, R. T. (2008). Promoting early adolescents' achievement and peer relationships: The effects of cooperative, competitive, and individualistic goal structures. Psychological Bulletin, 134(2), 223-246.

Rubin, K. H., Bukowski, W. M., \& Bowker, J. C. (2015). Children in peer groups. In M. H. Bornstein \& T. Leventhal (Eds.), Handbook of child psychology and developmental science (7th ed., pp. 321-412). New York, NY: Wiley \& Sons.

Rubin, K. H., Bukowski, W. M., Parker, J. G., \& Bowker, J. C. (2006). Peer interactions, relationships, and groups. In W. Damon \& R. M. Lerner (Eds.), Child and adolescent development: An advanced course (pp. 2-82). New York, NY: Wiley \& Sons.

Sarrasin, O., Green, E. G.T., Fasel, N., Christ, O., Staerklé, C., \& Clémance, A. (2012). Opposition to anti-racism laws across Swiss municipalities: A multilevel analysis. Political Psychology, 33, 651-681.

Simpson, E. H. (1949). Measurement of diversity. Nature, 163, 168.

Swiss Federal Statistical Office. (2016). Migration and integration. Retrieved from http://www.bfs.admin.ch/bfs/portal/en/index/the men/01/07.html.

Tropp, L. R., \& Prenovost, M. A. (2008). The role of intergroup contact in predicting children's interethnic attitudes: Evidence from meta-analytic and field studies. In S. R. Levy \& M. Killen (Eds.), Intergroup attitudes and relations in childhood through adulthood (pp. 236-248). New York, NY: Oxford University Press.

Zarbatany, L., McDougall, P., \& Hymel, S. (2000). Genderdifferentiated experience in the peer culture: Links to intimacy in preadolescence. Social Development, 9(1), 62-79. 